\title{
PHARMACEUTICAL ANALYSIS AND DIABETES MELLITUS - A REVIEW
}

\author{
SOWMYALAKSHMI VENKATARAMAN ${ }^{1 *}$, MERUGU MANASA ${ }^{2}$
}

${ }^{1}$ Department of Pharmaceutical Chemistry and Analysis, School of Pharmaceutical Sciences, Vels Institute of Science, Technology and Advanced Studies (VISTAS), Chennai, Tamil Nadu, India. ${ }^{2}$ Research Scholar, Department of Pharmaceutical Chemistry and Analysis, School of Pharmaceutical Sciences, Vels Institute of Science, Technology and Advanced Studies (VISTAS), Pallavaram, Chennai, Tamil Nadu, India. Email: sowmyamahesh30@gmail.com

Received: 10 October 2018, Revised and Accepted: 11 December 2018

\section{ABSTRACT}

Context: Current review focuses on the importance of pharmaceutical analytical techniques in the diagnosis of diabetes and the study of antidiabetic drugs.

Objective: The main objective of the review is to compile the different analytical tools such as UV-spectroscopy, Fourier-transform infrared (FT-IR), nuclear magnetic resonance (NMR), liquid chromatography-mass spectrometry (LC-MS), gas chromatography (GC)-MS, and electrophoresis that are used to diagnose diabetes using different analytical methods. It also attempts to provide information on the assay of antidiabetic drugs by various analytical techniques and thus helps in the development of novel methods for the study of newer drugs molecules having antidiabetic activity.

Methods: The blood sample is subjected to centrifugation to collect the serum before any analytical estimation of antidiabetic drugs. The different types of diabetes were diagnosed using various analytical techniques such as UV-spectroscopy, FT-IR, NMR, LC-MS, GC-MS, and electrophoresis.

Results: Different analytical methods that were reported in the literature, were succinctly discussed about the quantification of various antidiabetic drugs. These methods were also employed for the determination of antidiabetic drugs in the research field for the study of actives pharmaceutical ingredients, marketing dosage forms, and post-marketed dosage forms.

Conclusion: This review is compiled in such a manner such that it helps the analysts to diagnose diabetes using different analytical techniques and also to study various antidiabetic drugs in the pharmaceutical research field. It also attempts to provide information about different active pharmaceutical ingredients, marketing dosage forms, and post-marketed dosage forms.

Keywords: Diabetes, Pharmaceutical analysis, Diagnosis, Antidiabetic drugs, UV spectroscopy, Fourier-transform infrared, Nuclear magnetic resonance, High-performance liquid chromatography, Electrophoresis.

(C) 2018 The Authors. Published by Innovare Academic Sciences Pvt Ltd. This is an open access article under the CC BY license (http://creativecommons. org/licenses/by/4. 0/) DOI: http://dx.doi.org/10.22159/ajpcr.2018.v11s4.31702

\section{INTRODUCTION}

Diabetes mellitus (DM) is caused due to the insufficient secretion of insulin. DM is considered as a metabolic disorder due to the longterm tissue or organ damage. It may also occur due to the damage of kidney or vascular system or nervous system [1]. In diabetes, blood sugars levels are increased for a prolonged period due to the group of metabolic diseases [2]. Diabetes is also characterized by a reduction in the protein, carbohydrate, and fat metabolism due to the insulin deficiency, thus causing chronic hyperglycemia [3].

According to the WHO guidelines, diabetes is classified into several types.

\section{DM}

Regardless of reasons DM is divided into two types.

a. Insulin-dependent DM (IDDM): To control the body metabolism insulin is required. Insulin secreted in the body is not sufficient to control the metabolism; hence, insulin is administered into the body externally to get normal glycemic levels.

b. Non-IDDM: This type of diabetes can be controlled with the help of oral hypoglycemic drugs which, in turn, can control blood glucose levels.

Impaired glucose tolerance (IGT) or impaired glucose regulation and impaired fasting glycemia (IFG)

The terms IGT and IFG, both are different, where IGT measure glucose levels in post-prandial state and IFG measures glucose levels in fasting conditions. A stage of IGT indicates the progress in the risk of diabetes, macrovascular, and cardiovascular disorders. IFG indicates cardiovascular disorder. IFG levels are always less than the normal glucose levels because it is usually measured under fasting condition [3].

If IFG levels $100-125 \mathrm{mg} / \mathrm{dl}$ or $5.6 \mathrm{mmol}-6.9 \mathrm{mmol} / \mathrm{L}$ and IGT levels are in the range of $140-199 \mathrm{mg} / \mathrm{dl}$ are considered acceptable [4].

\section{Normoglycemia}

Fasting glucose levels around $6 \mathrm{mmol} / \mathrm{L}$ are considered as normal levels. Such results also may have IGT or normal glucose tolerance. The values beyond this level lead to macro- or micro-vascular diseases [3].

\section{Etiological types}

Based on a-etiological factors diabetes is divided into the following types:

\section{Type-I diabetes}

Type-I diabetes is usually progresses due to the dysfunction of $\beta$ cells present in the pancreas, leads to a deficiency in insulin production. $\beta$-Cells are destroyed by anti-glutamic acid decarboxylase, islet cell or insulin antibodies. Due to this condition absolute insulin deficiency occurs $[3,5]$.

\section{Type-II diabetes}

Insulin resistance and deficiency of relative quantities of insulin are characteristic features of Type-II diabetes. Both can be present at a 
time and either of the conditions predominant clinically. The reason for this type is unknown even though this is a common type of diabetes [3].

\section{Gestational hyperglycemia}

It occurs during the pregnancy and may improve or recover after the delivery. Gestational hyperglycemia condition is similar to that of TypeII diabetes. Gestational diabetes causes health issues in the fetus or pregnant women. After the birth, the child may have congenital cardiac and central nervous system disorders, malformations of skeletal muscle, heavyweight and respiratory distress syndrome. Sometimes perinatal death may also occur due to the hyperbilirubinemia $[2,3]$. In the first trimester of pregnancy, the risk of gestational diabetes is very much high. In general, the diagnosis of gestational diabetes is carried out between 24 and 28 weeks of pregnancy [3].

\section{Complications of diabetes}

Based on the complications diabetes can be divided into two types.

1. Acute problems

2. Chronic complications.

\section{Acute problems}

It also termed as a medical emergency in diabetes, for example, diabetes ketoacidosis and hypoglycemia.

\section{Chronic complications}

It includes microvascular complications and macrovascular complications. It includes hyperglycemia and hypoinsulinemia or other metabolic disorders associated with them.

a. Microvascular problems: This also called as microangiopathic. This includes diabetes retinopathy, diabetic neuropathy, and some diabetic skin problems.

b. Macrovascular problems: This includes hypertension, arteriosclerosis, and cerebrovascular disease.

c. Other associated metabolic abnormalities: Other abnormalities include hypercholesterolemia.

\section{Signs and symptoms}

Polyuria, weight loss, polydipsia, and polyphagia are common symptoms of diabetes. Along with this blurry vision, headache, fatigue, reduced healing capacity, and itchy skin are also observed. Sometimes dehydration may also occur [2].

\section{Prevention}

It is always said that prevention is better than cure. Type-II diabetes can be prevented by physical exercise, maintaining normal weight, and diet regulation. Healthy diet includes rich in whole grain, fiber, good fats present in vegetable oils, nuts, and fish. Smoking and consumption of alcohol increase the occurrence of diabetes and hence should be avoided [2].

\section{Treatment}

a. Type-I diabetes: Insulin or semi-synthetic insulin is administered according to the weight, age, and sex of the patient.

b. Type-II diabetes: Metformin is the most widely used drug for this type of diabetes. Other types of oral hypoglycemic drugs are also prescribed depending on the conditions. In addition, angiotensinconverting enzyme inhibitors can also be used in the treatment of this type of diabetes [2].

\section{Treatment}

a. Type-I diabetes: Insulin or synthetic insulin is administered according to the weight, age, and sex of the patient (Fig. 1).

b. Type-II diabetes: Metformin is the most preferred drug for this type of diabetes (Fig. 2). Angiotensin-converting enzyme inhibitors are also used for the treatment Type-II diabetes [2,6].

\section{Study of antidiabetic drugs}

Study of antidiabetic drugs can be carried out by various analytical techniques in the pharmaceutical research field from drug development to marketing and post-marketing. Study of active pharmaceutical ingredients, dosage forms, impurities, intermediate products, diagnosis of diseases, biological samples, and degradation products can also be performed. Analytical techniques include titrimetry, spectroscopy, chromatography, electrophoresis, and other electrical methods [7].

Pharmaceutical analytical techniques used in the study of drugs.

\section{Titrimetry and electrical methods}

Titrimetric methods include acid-base titration, oxidation-reduction, complexometry, precipitation titration, non-aqueous titrations, and diazotization titration. These methods are conventional methods and were used in the analysis in earlier days. Now, they are have been replaced by electrical methods such as potentiometry, conductometry, and amperometry. Using these methods then there is an improvement in the endpoint detection, accuracy, and precision; in addition, it saves the labor, cost incurred, and time. Titrimetric methods can also be used for the estimation of degradation products [7], for example, metformin hydrochloride (non-aqueous titration) [8], tolazamide (non-aqueous titration) [9], and pioglitazone- $\mathrm{HCl}$ (Acid-base titration) [10].

\section{Chromatographic techniques}

Chromatography is an important analytical tool used for the separation of compounds according to their affinity toward the stationary phase. No single molecule have the same affinity due to difference in their molecular structure or composition [11].

\section{Thin-layer chromatography (TLC)}

In the TLC method, a thin layer of $0.25 \mathrm{~mm}$ thickness solid adsorbents acts as a stationary phase. To increase the adherence capacity of adsorbent to plate's binders is mixed with adsorbents as listed in Table 1 while preparing the slurry. The plates or sheets used for the preparation of TLC plates are made out of glass, plastic, or aluminum. Sample molecules are dissolved in suitable solvents, and the sample solution is applied to TLC plates with the help of micropipette at the bottom of the plate. TLC plate is introduced into the chamber which consists of mobile phase usually as a mixture of solvents. Mobile phase moves over the plate with the help of capillary action, and as a result, separation of molecules occurs according to the affinity.

This method used for the high degree of separation and purification of organic and inorganic samples with low cost. It also used for determination of impurities [7,11], for example, metformin [12-14], pioglitazone hydrochloride [15], glibenclamide, glimepiride [15,16], dasatinib [17], chlorpropamide [18], rosiglitazone [19], and nateglinide [14].

\section{High-performance liquid chromatography (HPLC)}

HPLC is the most preferred method of analysis in recent times. HPLC is a powerful qualitative and quantitative analytical technique, which are able to separate similar analytes present in the mixtures. Separation of molecules occurs in the column in short time under high pressure [7,11]. Simultaneous estimation of compounds also possible using HPLC, for example, tolbutamide [20], glibenclamide [21,22], glipizide [22], glimepiride [22], acarbose [23], miglitol [24], bromocriptine [25], alogliptin [26], metformin [26,27], albiglutide [28], liraglutide [29], linagliptin [30], saxagliptin [27], sitagliptin [31], nateglinide [32,33], exenatide [34], repaglinide [35], dapagliflozin [36], canagliflozin [37], gliclazide [38], glyburide [39], chlorpropamide [40], tolbutamide [41], rosiglitazone [42], and pioglitazone hydrochloride [43].

\section{Gas chromatography (GC)}

GC is used for the separation of volatile compounds. Gas LC plays an important role in the analysis of pharmaceutical dosage forms. Impurities and residual solvents present in traces amount also detected by GC [11], for example, metformin [44] and chlorpropamide [45]. 


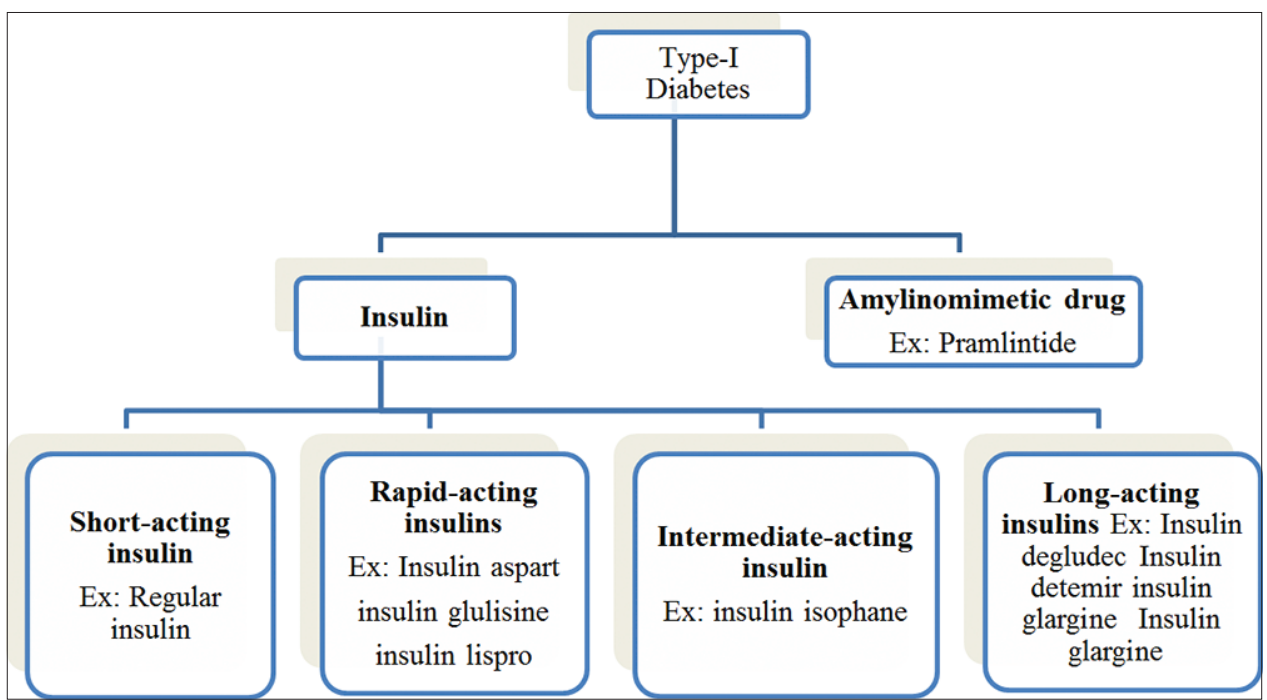

Fig. 1: Type-I antidiabetic drugs

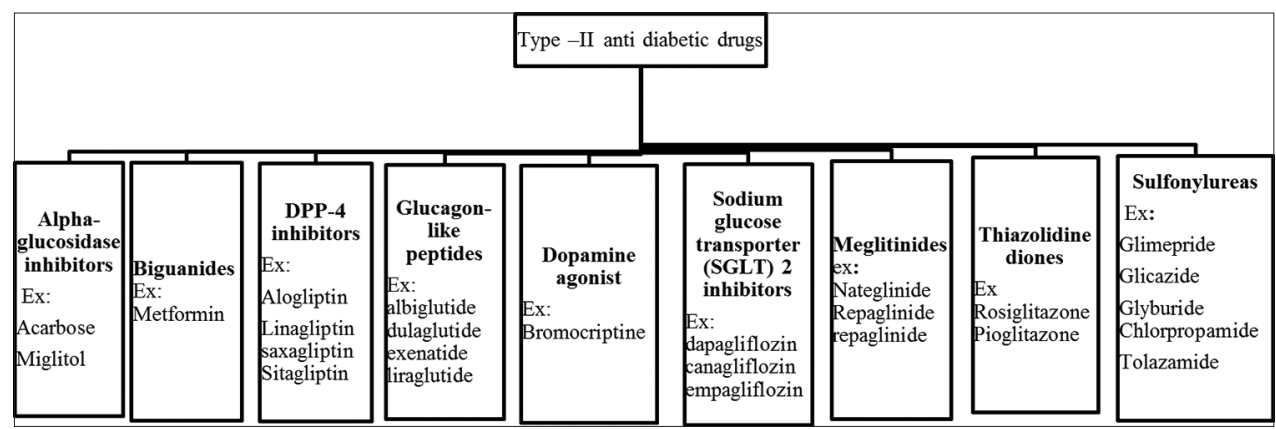

Fig. 2: Type-II antidiabetic drugs

\section{SPECTROSCOPIC METHODS}

\section{Ultraviolet-visible spectroscopy}

In UV spectrophotometry, the excitation of electrons present in the sample molecules occurs easily by absorption of high energy of light in the range of 200-800 $\mathrm{nm}$. The molecules with conjugated pielectrons are able to absorb the radiation in this region [11].In this type of spectroscopy reflection or transmission properties of molecules are used for the quantitative analysis as a function of wavelength, for example, glibenclamide [46,47], metformin [8,48], acarbose [49], miglitol [49,50], alogliptin [50], linagliptin [51], saxagliptin [52], Sitagliptin [53], nateglinide [54], repaglinide [55], dapagliflozin, [56], canagliflozin [57], empagliflozin [58], glimepiride [59], glipizide [60], and chlorpropamide [61].

\section{Infrared (IR) spectroscopy}

Molecules or atoms produce vibrational and rotational excitation by absorbing energy radiation in the IR region. The different bands produced correspond to characteristic absorption of radiation and thus helps to identify different functional groups present in the drug molecules. Qualitative, quantitative, multi component analysis and simultaneous estimation are possible by using IR spectroscopy $[7,11]$, for example, Metformin [48].

\section{Nuclear magnetic resonance (NMR) spectroscopy}

An NMR spectrum is produced due to the excitation of spin state of molecules in the presence of radio frequency rays. NMR spectroscopy is divided into various types such as $\mathrm{H}^{1}, \mathrm{C}^{13}, \mathrm{~F}^{19}$, and $\mathrm{P}^{31}$. This method is used for qualitative analysis, to identify the structure of the drug molecules present in pharmaceuticals and biological samples.
Determination of impurity and characterization is also done using NMR spectroscopy [7,11], for example, metformin [62].

\section{Fluorimetry}

Fluorescence spectroscopy is used for the quantitative analysis of drug molecules present in drug products and biological samples. This method gives precise and sensitive results [11], for example, rosiglitazone maleate [63] and nateglinide [64].

\section{Electrophoresis}

Electrophoresis method has become an important technique in pharmaceutical analysis. Capillary electrophoresis (CE) is the best method to separate charged particles through the capillary tube in the presence of an electric field. CE is used for the qualitative and quantitative analysis of charged molecules. This method requires small amount of sample in aqueous condition. Biopolymers and inorganic ions can be separated by CE [7], for example, sitagliptin [65] and metformin [65].

\section{HYPHENATED TECHNIQUES}

\section{LC-mass spectrometry (MS)}

HPLC connected with MS with various interfaces. Effluent from the column of HPLC enters into the MS through the interface. In MS, ions are generated and sent to electron multiplier tubes. Ionization occurs using two methods, namely Atmospheric pressure chemical ionization and ESI or APESI: (Atmospheric pressure) or electrospray ionization. Drugs molecules, degradants identification, characterization of impurities, and separation of components occur by LC-MS method [7,11], for example, acarbose [66], miglitol [24], glimepiride [67], dapagliflozin [68], canagliflozin [69], Linagliptin [70], sitagliptin [71], saxagliptin [72], and bromocriptine [73]. 
Table 1: Types of adsorbent

\begin{tabular}{|c|c|c|c|}
\hline S. No & Type of adsorbent & Adsorbent & Formula \\
\hline 1 & Most strong adsorbent & $\begin{array}{l}\text { Alumina } \\
\text { Charcoal } \\
\text { Florisil }\end{array}$ & $\begin{array}{l}\mathrm{Al}_{2} \mathrm{O}_{3} \\
\mathrm{C} \\
\mathrm{MgO} / \mathrm{SiO} \text { (anhydrous) }\end{array}$ \\
\hline 2 & Least strong adsorbent & Silica gel & $\mathrm{SiO}_{2}$ \\
\hline
\end{tabular}

\section{GC-MS}

GC connected with MS with various interfaces. Effluent from the column of GC enters into the MS through the interface. Identification of drug molecules and their degradants, characterization of impurities, bioassay, and separation of components can be analyzed using LC-MS method, for example, metformin [74].

\section{DIAGNOSIS}

Diagnosis of diabetes can be done by determining the blood glucose levels. In fasting conditions, the blood glucose level could be $>6.7 \mathrm{mmol} / \mathrm{L}$ or random glucose levels will be more than $10 \mathrm{mmol} / \mathrm{L}$ considered as diabetes. If there occur any doubts in the diagnosis, glucose tolerance test have to be conducted to measure the blood glucose level. Before the test, the patient needs to be on fast at least for 10-12 h. During the test, the patient is advised to take $75 \mathrm{mg}$ glucose orally and the test will be repeated after $2 \mathrm{~h}$. Thus, from the results observed, one can determine the glucose tolerance of the patient [5].

In the diagnosis process, glucose levels can be determined using various analytical methods.

\section{UV spectroscopy}

The glucose level of the blood can be determined by comparison of the UV spectrum of normal serum and diabetic blood serum. Diabetes leads to changes in the metabolism of fats, carbohydrates, and proteins. Blood samples are usually collected from normal and diabetic people, and the serum is separated by centrifugation of the blood samples. The separated serum will further be diluted with deionized water and absorbance of the spectrum will be analyzed [75].

\section{Fourier-transform (FT)-IR}

Diabetic conditions induce alterations in the content of macromolecules and their concentrations, changes in the structure and size of tissues. FT-IR is used to determine these changes. Renal plasma membrane was separated, and fats were removed from tissue at 0 to $4^{\circ} \mathrm{C}$. In general, the tissue will be placed in mannitol and buffer for homogenization. After homogenization, the sample will be mixed with calcium chloride solution (10 mM) and diluted with buffer and centrifuged for $12 \mathrm{~min}$. The sediment separated will be dissolved in buffer solution and recentrifuged again. The sediment, thus, obtained will be dissolved in the supernatant, and this sample solution will be analyzed using FT-IR windows [76]

\section{NMR}

Identification of metabolite is usually done using NMR spectroscopy in diabetes. The collected urine samples are stored in frozen condition. The frozen urine sample is maintained in ice for $30 \mathrm{~s}$, and $500 \mu \mathrm{L}$ of the sample will be mixed with buffer. The NMR spectrum for this sample solution will be taken and the spectrum thus obtained will be compared with the spectra of normal urine and diabetic patient's urine [77].

\section{Gel electrophoresis}

Type-I diabetes affects the function of the salivary gland. Protein modification in the saliva indicates Type-I diabetes. After $2 \mathrm{~h}$ of breakfast make the subject to rinse mouth with water and paraffin has to be chewed. The saliva was collected for $5 \mathrm{~min}$ in a tube containing protease inhibitor, and it is stored at $-20^{\circ} \mathrm{C}$. The sample solution was applied to the general the gel electrophoresis strips were applied with the sample solution and allow to equilibrate in buffer solution for 15 min. A constant voltage is applied to the strips, and the proteins are allowed proteins to separate. Gel images are digitalized. The comparison of healthy subject saliva protein with diseased subject saliva can be helpful in the determination of Type-I diabetes [78].

\section{LC-MS and GC-MS}

For carrying out the analysis, a $20 \mathrm{~mL}$ of the antecubital venous blood sample is collected and processed at $80^{\circ} \mathrm{C}$ for $6 \mathrm{~h}$ to collect the serum and is allowed to stand overnight at $4^{\circ} \mathrm{C}$ to achieve metabolic profiling. These samples are diluted to get $30 \mu \mathrm{g} / \mathrm{mL}$. The samples were added with internal standard and centrifuged for $10 \mathrm{~min}$. The supernatant was used for metabolite profiling using LC-MS or GC-MS method. The presence of amino acids such as leucine, isoleucine, and valine, free fatty acids such as palmitic acid and stearic acid and lysophosphatidylinositol confirms the occurrence of the diabetic condition [79].

In recent times $\mathrm{HbA} 1 \mathrm{c}$, the glycated hemoglobin has been considered as an important marker for the diagnosis of diabetes. Usually, HbA1c analytical methods are in general based on the differences in charge or structure. The different analytical techniques include ion-exchange chromatography, CE, affinity chromatography, and immunoassay. Other analytical methods include immunoturbidimetry and ionexchange HPLC. Among these methods, HbA1c measured using HPLC was significantly higher than compared to other immunoturbidimetric methods [80].

\section{CONCLUSION}

The present review discusses the types of diabetes and various analytical methods used for the diagnosis of diabetes and to study the different antidiabetic drugs in a comprehensive manner. This will help the future researchers about the different analytical methods that are available for the diagnosis of diabetes and the assay of antidiabetic drugs and thus helps in the development of novel methods for the study of antidiabetic newer drugs molecules.

\section{ACKNOWLEDGMENTS}

The authors are thankful to the management of Vels Institute of Science, Technology and Advanced Studies (VISTAS), for providing the necessary library facilities, infrastructure, and equipment for carrying out the research work.

\section{AUTHORS' CONTRIBUTIONS}

The authors SV and MM had contributed equally toward the collection of literature and preparation of the manuscript.

\section{CONFLICTS OF INTEREST}

The authors declare that they have no conflicts of interest.

\section{REFERENCES}

1. Severcan F. FTIR spectroscopy as a novel method in characterization and diagnosis of Type I diabetes in rat animal model and the protective role of antioxidants. J Diabetes Metab 2013;4:14-16.

2. Shouip HA. Diabetes Mellitus. Resgate; 2014. https://www. researchgate.net/publication/270283336_Diabetes_mellitus.

3. Definition, Diagnosis and Classification of Diabetes Mellitus and its Complications, Part 1: Diagnosis and Classification of Diabetes Mellitus. World Health Organization Department of Noncommunicable Disease Surveillance Geneva 1999. https://www.staff.ncl.ac.uk/philip. home/who_dmg.pdf.

4. Kerner W, Brückel J, German Diabetes Association. Definition, classification and diagnosis of diabetes mellitus. Exp Clin Endocrinol Diabetes 2014;122:384-6.

5. Squirrell D, Bush J. Diabetes Mellitus. http://www.oia.org.uk/userFiles/ File/PDF/Diabetes.pdf.

6. A Complete List of Diabetes Medications. https://www.healthline.com/ health/diabetes/medications-list.

7. Siddique MR, Alothman ZA, Rahaman N. Analytical techniques in pharmaceutical analysis: A review. Arabian J Chem 2013;44Suppl 1:1-13. 
8. Silpavathi L, Das MK. A non-aqueous titrimetry and UV spectrophotometric study of metformin hydrochloride marketed tablets. J Chem Pharm Sci 2015;8:128-30.

9. Brittain HG. Assay of tolazamide by titration. In: Analytical Profiles of Drug Substances and Excipients. Vol. 22. London: Academic Press; 1993. p. 511.

10. Bratty MA, Hashem H, Eranhiyil S. Visual, potentiometric and conductometric acid-base titrations for determination of antidiabetic pioglitazone-HCl. Int J Bio Pharm Allied Sci 2016;5:93-103.

11. Khan I, Mulpuri K, Das B, Mohiuddin MD, Rahman MH. Analytical techniques (chromatography, spectroscopy electrophorosis) in pharmaceutical analysis: A review. Int $J$ Res Pharm Nano Sci 2015;4:19-22.

12. Havele S, Dhaneshwar S. Estimation of metformin in bulk drug and in formulation by HPTLC. J Nanomed Nanotech 2009;1:1-3.

13. Sondarva C, Shah K. Development and validation of HPTLC method for simultaneous estimation of anti-diabetic drugs from their combined dosage form. Int J Pharm Pharm Res 2018;11:192-211.

14. Thomas AB, Patil SD, Nanda RK, Kothapalli LP, Bhosle SS, Deshpande AD, et al. Stability-indicating HPTLC method for simultaneous determination of nateglinide and metformin hydrochloride in pharmaceutical dosage form. Saudi Pharm J 2011;19:221-31.

15. Filipic S, Popovic G, Nikolic K, Agbaba D. TLC determination of glimepiride and its main impurities in pharmaceuticals. J Liquid Chrom Relat Tech 2013;36:2422-30.

16. Dhaneshwar SR, Salunkhe JV, Bhusari VK. Validated HPTLC method for simultaneous estimation of metformin hydrochloride, atorvastatin and glimepiride in bulk drug and formulation. J Anal Bioanal Tech 2010;1:1-5.

17. Bhole R, Bonde C, Birada P. Development and validation of stability indicating hptlc method for estimation of dasatinib and characterization of degradation products by using mass spectroscopy. Eurasian J Anal Chem 2018; 13:em33.

18. Ali NW, Abdelwahab NS, EL-Zeiny BA, Tohamy SI. Stability indicating TLC-densitometric method for determination of chlorpropamide. J Liquid Chrom Relat Tech 2013;36:1575-85.

19. Walode SG, Chaudhari HK, Saraswat MS, Kasture AV, Wadodkar SG. Validated high performance thin layer chromatographic determination and content uniformity test for rosiglitazone in tablets. Indian J Pharm Sci 2010;72:249-52

20. Raghow G, Meyer MC. High-performance Liquid Chromatographic assay of tolbutamide and carboxytolbutamide in human plasma. J Pharm Sci 1981;70:1166-8.

21. Adl SM, Sadek ME, Hasan MH. Design and validation of stability indicating assay of glibenclamide using RP-HPLC technique in both bulk, pharmaceutical formulations and human plasma. J Appl Pharm 2017:9:1-6.

22. Rao U, Nikalje AP. Determination of Glipizide, Glibenlamide and Glimeperide in a tablet dosage form in the presence of metformin hydrochloride by ion pair-reversed phase liquid chromatographic technique. J Anal Bioanal Tech 2010;1:1-5.

23. Daali Y, Cherkaoui S, Cahours X, Veuthey JL. High performance liquid chromatography of acarbose and its metabolite on porous graphitic carbon column. J Sep Sci 2002;25:280-4.

24. Balakumaran K, Janagili M, Rajana N, Papureddy S, Anireddy J. Development and validation of miglitol and its impurities by RP-HPLC and characterization using mass spectrometry techniques. Sci Pharm 2016:84:654-70.

25. Ashour S, Kattan N. New sensitive method for determination of bromocriptine in tablets by high performance liquid chromatography. R J Aleppo Univ 2013;87:1-10.

26. Sundar PS, Tabassum I, Vasanthi R, Raja MA, Rao KN, Dutt KR, Mahesh M. Development and validation of stability indicating rp-hplc method for the simultaneous estimation of alogliptin and metformin in bulk and pharmaceutical dosage form. Indo Am J Pharm 2017;3:223-33.

27. Cumar RP, Vasudevan M, Deecaraman. A validated RP-HPLC method for simultaneous estimation of metformin and saxagliptin in tablets. Rasayan J Chem 2012;5:137-41

28. Susena S, Prakash KV. A novel validated RP-HPLC method for the estimation of albiglutide in bulk. Int $\mathrm{J}$ Pharm Chem Bio Sci 2013;3:504-9.

29. Satyanarayana PV, Madhavi AS. Validated RP-HPLC method for the estimation of liraglutide in tablet dosage. Int J Sci Invent Today 2012;1:17-26.

30. Raju Badugu LR. A validated RP-HPLC method for the determination of linagliptin. Am J PharmTech Res 2012;2:462-70.

31. Ravisankar P, Hassain SK, Neeha SM. Novel RP-HPLC method for simultanious determination of sitagliptin and simvastation in bulk and tablet dosage form. IOSR J Pharm 2015;5:34-40

32. Hacioglu A, Citlak A, Karakus U. Development and validation of an HPLC method for determination of nateglinide in drug substances. Marmara Pharm J 2015;19:103-8.

33. Sudheer C, Rao BT, Madhavi S, Rambabu C. A validated stability indicating RP-HPLC method for estimation of natiglinide in bulk and pharmaceutical dosage forms. Eur J Pharm Med Res 2016;3:265-70.

34. Bachhav YG, Kalia YN. Development and validation of a rapid highperformance liquid chromatography method for the quantification of exenatide. Biomed Chromatogr 2011;25:838-42.

35. Pingale PL, Nandasana PV. Development and validation of RPHPLC method for the estimation of repaglinide in bulk drug and pharmaceutical formulation. Intern J Drug Dev Res 2012;4:247-52.

36. Mante GV, Hemke AT, Umekar MJ. RP-HPLC method for estimation of dapagliflozin from its tablet. Intern J Chem Tech Res 2018;11:242-8.

37. Marella VL, Syed A, Prasanna LM, Nalluri BN. A novel validated RP-HPLC method for the estimation of canagliflozin in bulk and pharmaceutical dosage forms. Int J Adv Pharm Anal 2017;7:24-7.

38. Ghai D, Ganesh GL. HPLC method for determination of gliclazide in human serum. Asian J Chem 2009;21:4258-64.

39. Gedeon C, Kapur B, Aleksa K, Koren G. A simple and rapid HPLC method for the detection of glyburide in plasma original research communication (analytical). Clin Biochem 2008;41:167-73.

40. Basavaiah K, Rajendraprasad N. High performance liquid chromatographic assay of chlorpropamide, stability study and its application to pharmaceuticals and urine analysis. Austin J Anal Pharm Chem 2017;4:1-7.

41. Latha DM, Ammania M, Kumar PJ. Development and validation of RP-HPLC method for quantitative analysis tolbutamide in pure and pharmaceutical formulations. Int J Chem Sci 2013;11:607-14.

42. Pedersen RS, Brosen K, Nielsen F. HPLC method for determination of rosiglitazone in plasma. Chromatographia 2005;62:197-201.

43. Prasad PS, Imam SS, Aqil M, Rizwan M, Sultana Y, Ali A. Validated reversed phase HPLC method for determination of pioglitazone hydrochloride in bulk drug and tablet formulations. J Anal Chem 2015;70:744-6.

44. Lennard MS, Casey C, Tucker GT, Woods HF. Determination of metformin in biological samples. Br J Clin Pharmacol 1978;6:183-5.

45. Sabih K, Sabih K. Gas chromatographic method for determination of tolbutamide and chlorpropamide. J Pharm Sci 1970;59:782-4.

46. Parameswararao K, Satynarayana MV, Raju TN, Ramana GV. Novel spectrophotometric methods for the assay of glibenclamide in pure and dosage forms. Der Pharm Chem 2012;4:2449-52.

47. Eapen C, Prasanth VG, Rai A. Development of UV spectrometric method of glibenclamide (glyburide) in bulk and pharmaceutical formulations. Int J Chem Tech Res 2012;4:356-60.

48. Sheela NR, Muthu S, Krishnan SS. FTIR, FT Raman and UV-Visible spectroscopic analysis on metformin hydrochloride. Asian J Chem 2010;22:5049-56.

49. Ibrahim FA, Ali FA, Ahmed SM, Tolba MM. Kinetic determination of acarbose and miglitol in bulk and pharmaceutical formulations using alkaline potassium permanganate. Int J Biomed Sci 2007;3:20-30.

50. Chirag, Parle A. Development and validation of UV spectrophotometric method for simultaneous estimation of metformin hydrochloride and alogliptin benzoate in bulk drugs and combined dosage forms. Der Pharm Chem 2014;6:303-11.

51. Zalte AG, Saudagar RB, Nanasahe P, Katkade. Validated UVspectroscopic estimation of linagliptin concentration in bulk and dosage form. Res J Pharm Tech 2016;9:490-2.

52. Kalaichelvi R, Jayachandran, Reddy KC. Validated spectroscopic method for estimation of saxagliptin in pure and from tablet formulation. Int J Pharm Pharm Sci 2011;3:179-80.

53. Pritam J, Amar C, Bhargav C, Shani P, Santsaran P, Shimpi. Development and validation of first order derivative UV-Spectrophotometric method for determination of sitagliptin in bulk and in formulation. Int J Drug Dev Res 2011;3:194-9.

54. Jain S, Bhandari A, Purohit S. Spectrophotometric determination of nateglinide in bulk and tablet dosage forms. Asian J Pharm 2009;3:218-21

55. Mishra J, Nayak SK, Sahoo SK. Development, validation and stability study of UV spectrophotometric method for determination of repaglinide in bulk and pharmaceutical dosage forms. J Innov Appl Pharm Sci 2016;1:10-6.

56. Mante GV, Gupta KR, Hemke AT. Estimation of dapagliflozin from its tablet formulation by UV-Spectrophotometry. Pharm Methods 2017;8:102-7. 
57. Kaur I, Wakode H, Singh HP. Development and validation of UV spectroscopic method for determination of canagliflozin in bulk and pharmaceutical dosage form. Pharm Methods 2015;6:82-6.

58. Ayoub BM, Emam RM, Youssef MM, El-Kattan MN, Sayed MA, Kowider AM, et al. Mean centering method for determination of empagliflozin and metformin. Marmara Pharm J 2017;21:669-74

59. Afieroho OE, Okorie O, Okonkwo TJ.An ultraviolet-spectrophotometric method for the determination of glimepiride in solid dosage forms. Diabetes Technol Ther 2011;13:671-4.

60. Karkhanis VV, Captain AD, Patel PH. Development and validation of uv spectrophotometric method for estimation of glipizide in bulk and pharmaceutical dosage forms. Int J Pharm Sci Res 2013;4:1865-7.

61. Mbah CJ, Okorie NH. Spectrophotometric determination of chlorpropamide in bulk and dosage form by complexation with chloranilic acid. J Sci Res 2011:3:207-12.

62. Gadape HH, Parikh KH. Quantitative determination and validation of metformin hydrochloride in pharmaceutical using quantitative nuclear magnetic resonance spectroscopy. E J Chem 2011;8:767-81

63. Walash MI, Brashy A, Enany N, Kamel ME. Spectrofluorimetric and spectrophotometric determination of rosiglitazone maleate in pharmaceutical preparations and biological fluids. Pharm Chem J 2009; 43:697-709

64. Karasakal A, Ulu ST. Spectrofluorimetric determination of nateglinide in pure and pharmaceutical preparations through derivatization with 4-chloro-7-nitrobenzo-2-oxa-1,3-diazole. Optics Spectro 2014; 116:52-5.

65. Salim M, El-Enany N, Belal F, Walash M, Patonay G. Simultaneous determination of sitagliptin and metformin in pharmaceutical preparations by capillary zone electrophoresis and its application to human plasma analysis. Anal Chem Insights 2012;7:31-46.

66. Novak P, Cindric M, Tepes M, Dragojevic S, Ilijas M, Mihaljevic K. Identification of impurities in acarbose by using an integrated liquid chromatography-nuclear magnetic resonance and liquid chromatography-mass spectrometry approach. J Sep Sci 2005;28:1442-7.

67. Yuzuak N, Ozden T, Eren S, Ozilhan S. Determination of glimepiride in human plasma by LC-MS-MS. Chromatographia 2007;66:165-8.

68. Aubry AF, Gu H, Magnier R, Morgan L, Xu X, Tirmenstein M, et al. Validated LC-MS/MS methods for the determination of dapagliflozin, a sodium-glucose co-transporter 2 inhibitor in normal and ZDF rat plasma. Bioanalysis 2010;2:2001-9.

69. Kobuchi S, Yano K, Ito Y, Sakaeda T. A validated LC-MS/MS method for the determination of canagliflozin, a sodium-glucose co-transporter 2 (SGLT-2) inhibitor, in a lower volume of rat plasma: Application to pharmacokinetic studies in rats. Biomed Chromatogr 2016;30:1549-55.

70. Ghany MF, Aziz OA, Ayad MF, Tadros MM. Pharmaceutical analysis of linagliptin and empagliflozin using LC-MS/MS. Der Pharm Chem 2016;8:186-9.

71. Salim MM, El-Enany N, Belal F, Walash M, Patonay G. Micelleenhanced spectrofluorimetric method for determination of sitagliptin and identification of potential alkaline degradation products using LC-MS. Luminescence 2014;29:65-73.

72. Ghany MF, Aziz OA, Ayad MF, Tadros MM. Stability-indicating liquid chromatographic method for determination of saxagliptin and structure elucidation of the major degradation products using LC-MS. J Chromatogr Sci 2015;53:554-64.

73. Salvador A, Dubreuil D, Denouel J, Millerioux L. Sensitive method for the quantitative determination of bromocriptine in human plasma by liquid chromatography-tandem mass spectrometry. J Chromatogr B Analyt Technol Biomed Life Sci 2005;820:237-42.

74. Goedecke C, Fettig IC, Philippa PR, Geissenc SU. A novel GC-MS method for the determination and quantification of metformin in surface water. Anal Methods 2017;10:1580-4.

75. Hussein RO, Hussein HH, Hamza ZM. Diagnosis of diabetes mellitus in serum of pregnant women by using UV spectroscopy technique. J Kufa Phys 2015;7:92-6.

76. Severcan F, Bozkurt O, Gurbanov R, Gorgulu G. FT-IR spectroscopy in diagnosis of diabetes in rat animal model. J Biophotonics 2010;3:621-31

77. Capati A, Ijare OB, Bezabeh T. Diagnostic applications of nuclear magnetic resonance-based urinary metabolomics. Magn Reson Insights 2017; 10:1178623X17694346.

78. Hirtz C, Chevalier F, Sommerer N, Raingeard I, Bringer J, Rossignol M, et al. Salivary protein profiling in Type 1 diabetes using twodimensional electrophoresis and mass spectrometry. Clin Proteomics 2006;2:117-27.

79. Lu Y, Wang Y, Ong CN, Subramaniam T, Choi HW, Yuan JM, et al. Metabolic signatures and risk of type 2 diabetes in a Chinese population: An untargeted metabolomics study using both LC-MS and GC-MS. Diabetologia 2016;59:2349-59.

80. Sherwani SI, Khan HA, Ekhzaimy A, Masood A, Sakharkar MK. Significance of hbA1c test in diagnosis and prognosis of diabetic patients. Biomark Insights 2016;11:95-104. 